\title{
Analysis of Retinal Nonperfusion Area and Ganglion Cell Layer Thickness in Branch Retinal Vein Occlusion by OCT-Angiography
}

\author{
Ana L Basílio, Luísa Vieira, Lívio Costa, Rita Proença, Sara Crisóstomo, Joana Cardigos, NunoMoura-Coelho and \\ Rita Flores* \\ Centro Hospitalar de Lisboa Central, Portugal \\ Submission: March 16, 2018; Published: April 16, 2018 \\ *Corresponding author: Rita Flores, Ophthalmology Department, Hospital de Santo António dos Capuchos, Alameda de Santo António dos Capuchos, \\ 1169-050 Lisboa, Portugal, Tel: +351967024175; Email: ritamariaflores@gmail.com
}

\begin{abstract}
Purpose: To analyze the area of retinal nonperfusion in branch retinal vein occlusion (BRVO) and its relation to retinal ganglion cell (RGC) layer thickness.

Procedures: Patients with ischemic BRVO, with no signs of fluid, were evaluated by Cirrus HD-OCT-A, Zeiss. Nonperfusion findings and RGC layer thickness were evaluated in a $6 \times 6 \mathrm{~mm}$ area centered in fovea.

Results: 10 eyes (8 patients) were included (mean age of 75.60 12.57 years min 60, max 88). Area of ischemia in deep plexus was superior to superficial plexus $(\mathrm{p}=0.013)$. There was a strong correlation between ischemic area of superficial and deep plexus $(\mathrm{r}=0.915 ; \mathrm{p}<0.001)$ and an important correlation between ischemic area of superficial plexus and area of reduced RGC layer thickness ( $r=0.661 ; p=0.038)$.

Conclusions: In ischemic BRVO, deep capillary plexus reveals a greater area of ischemia than superficial plexus. This study suggests that ischemia may cause the decrease of RGC layer thickness.
\end{abstract}

Keywords: BRVO; Capillary plexus; Ischemia; OCT-A; RGC layer thickness

\section{Introduction}

Retinal vein occlusion (RVO) is a common and sightthreatening retinal vascular disorder. Location of the occlusion, presence of macular edema and the extent of retinal nonperfusion influence the clinical characteristics, prognosis and response to treatment. Branch retinal vein occlusion (BRVO) is an occlusion of either a major branch retinal vein draining one quadrant of the retina, a macular branch vein draining a portion of the macula or a peripheral branch vein draining a portion of the retinal periphery. [1].

The Optical Coherence Tomography-Angiography (OCT-A) is a noninvasive diagnostic test that allows a better understanding of the effects of BRVO in both superficial and deep vascular plexus. The OCT-A device allows the integration of abnormalities in vascularity and structural changes [2-4].

BRVO microvascular changes have been studied through fluorescein angiography, however, the overlapping of the vascular networks makes it still poorly understood [2]. According to the literature, OCT-A shows capillary abnormalities (including disruption) and grayish areas (areas with reduced capillary density) in superficial and deep capillary plexus in patients with BRVO [5].

The aim of our study was to analyze the area of retinal nonperfusion in eyes with BRVO without macular edema and to compare the involvement of both plexus and its relation to retinal ganglion cell (RGC) layer thickness.

\section{Materials and Methods}

The authors conducted a retrospective observational study in agreement with the Declaration of Helsinki for research involving humans. Patients with the diagnosis of ischemic BRVO involving the macular area, without macular edema were included. All patients had been submitted to a ranibizumab scheme in acute phase of disease and the last treatment was at least 4 months earlier. Patients with other ocular or systemic diseases that could influence RGC layer thickness and whose images had artifacts were excluded. BRVO was diagnosed based on clinical findings and auxiliary testing (fluorescein angiography and OCT). These eyes were also evaluated by OCT-A (Cirrus HD-OCT Angiography, Zeiss). The studied variables were: age, gender, 
follow-up duration and best-corrected visual acuity, converted in logMAR for statistical evaluation. Nonperfusion findings and RGC layer thickness were evaluated in a $6 \times 6 \mathrm{~mm}$ macular area centered in fovea, captured by OCT-A device.

Sketch and Calc ${ }^{\mathrm{TM}}$ Software was used to calculate the areas. In order to determine the ischemic area in superficial and deep plexus, the area of capillary density loss was delimited (Figure
1A). To calculate the area of reduced thickness in RGC layer, the deviation area from the normal (based on the device database) was considered (Figure 1B). The images of both plexus and the images of RGC layer thickness were superimposed in order to analyze the congruence in the location of the alterations (ischemic areas of the plexus and areas of decrease in RGC layer thickness). The designed areas were confirmed by two other ophthalmologists, specialized in retina.
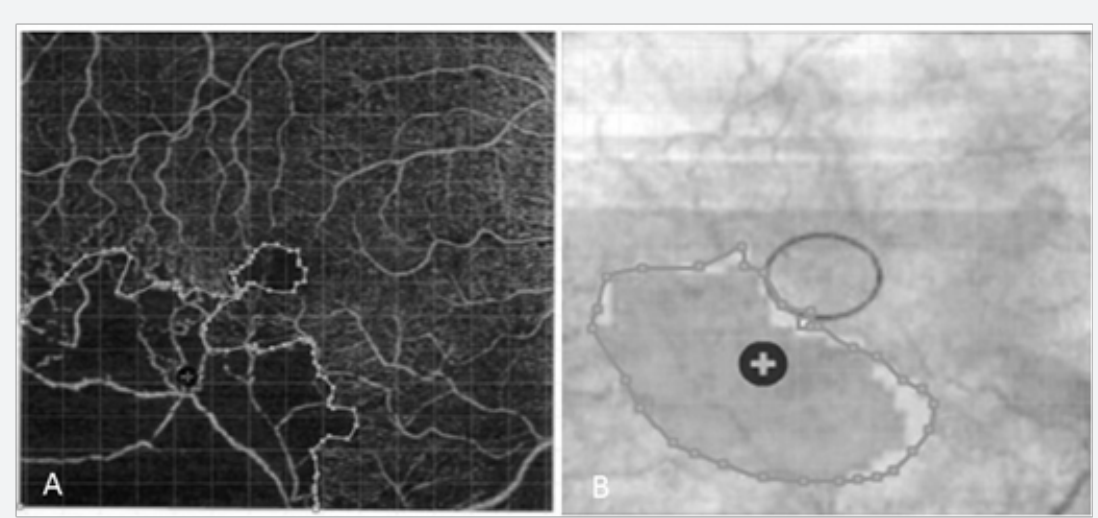

Figure 1: Example of delineated area of capillary density loss in superficial plexus (A) and of delineated area of reduced thickness in retinal ganglion cell layer (B).

Statistical analysis was performed using SPSS software version 23.0 (SPSS, Chicago, USA), using Wilcoxon test and Spearman's correlation. The $\mathrm{p}$-value inferior to 0.05 was considered statistically significant.

\section{Results}

Table 1: Detailed data of patients.

\begin{tabular}{|c|c|}
\hline Number of patients & 8 \\
\hline Number of eyes & 10 \\
\hline \multicolumn{2}{|c|}{ Age (years) } \\
\hline Mean & 75.6 \\
\hline Min. & 60 \\
\hline Max. & 88 \\
\hline SD & 12.57 \\
\hline \multicolumn{2}{|c|}{ Gender - n (\%) } \\
\hline Male & $5(62.5 \%)$ \\
\hline Female & $3(37.5 \%)$ \\
\hline \multicolumn{2}{|c|}{ Follow-up duration (months) } \\
\hline Mean & 13.43 \\
\hline Min. & 8 \\
\hline Max. & 25 \\
\hline SD & 9.74 \\
\hline \multicolumn{2}{|c|}{ BCVA (logMar) } \\
\hline Mean & 0.44 \\
\hline Min. & 0 \\
\hline Max. & 1 \\
\hline SD & 0.46 \\
\hline
\end{tabular}

Min: Minimum; Max: Maximum; SD: Standard Deviation; BCVA: BestCorrected Visual Acuity

This study included 10 eyes with ischemic BRVO from 8 patients. Patients had a mean age of $75.60 \pm 12.57$ years (range 60-88 years), 5 were males. Mean duration of follow-up was 13.43 \pm 9.74 months (range 8-25 months). Mean best-corrected visual acuity in $\log$ MAR was $0.44 \pm 0.46$ (range 0 -1). Table 1 shows the baseline characteristics of the patients.

Table 2: Ischemic areas of vascular plexus and area of reduction of RGC layer thickness.

\begin{tabular}{|c|c|}
\hline \multicolumn{2}{|c|}{ Ischemic area of superficial plexus $\mathbf{( m m}^{\mathbf{}} \mathbf{)}$} \\
\hline Mean & 7.77 \\
\hline Min. & 0.76 \\
\hline Max. & 21.36 \\
\hline SD & 6.72 \\
\hline Ischemic area of deep plexus $\mathbf{( m m}^{\mathbf{2}} \mathbf{~}$ & 10.07 \\
\hline Mean & 2.07 \\
\hline Min. & 29.13 \\
\hline Max. & 8.27 \\
\hline SD & 7.164 \\
\hline Area of reduction of RGC layer thickness (mm $\mathbf{~})$ \\
\hline Mean & 0.00 \\
\hline Min. & 14.05 \\
\hline Max. & 4.53 \\
\hline SD &
\end{tabular}

Min: Minimum; Max: Maximum; SD: Standard Deviation; RGC: Retinal Ganglion Cell 
The area of ischemia in deep plexus (mean $10.07 \pm 8.27 \mathrm{~mm}^{2}$ ) was superior to the ischemic area of superficial plexus (mean $\left.7.77 \pm 6.72 \mathrm{~mm}^{2}\right)(\mathrm{p}=0.013)$. The mean area of reduction of RGC layer thickness was $7.16 \pm 4.53 \mathrm{~mm}^{2}$ (Table 2).

There was a strong correlation between the ischemic area of the superficial and deep plexus $(\mathrm{r}=0.915 ; \mathrm{p}<0.001)$ and an important correlation between the ischemic area of the superficial plexus and the area of reduction of RGC layer thickness ( $r=0.661$; $\mathrm{p}=0.038$ ). The correlation coefficient between the ischemic area of deep plexus and the area of reduction of RGC layer thickness was $0.624(\mathrm{p}=0.054)$.

During the analysis of the coincidence in location of altered areas, in 6 eyes there were areas of non-ischemia-related decrease in RGC layer thickness (Figure 2). Areas of ischemia not related to atrophy were detected in 3 of 10 eyes (Figure 3).
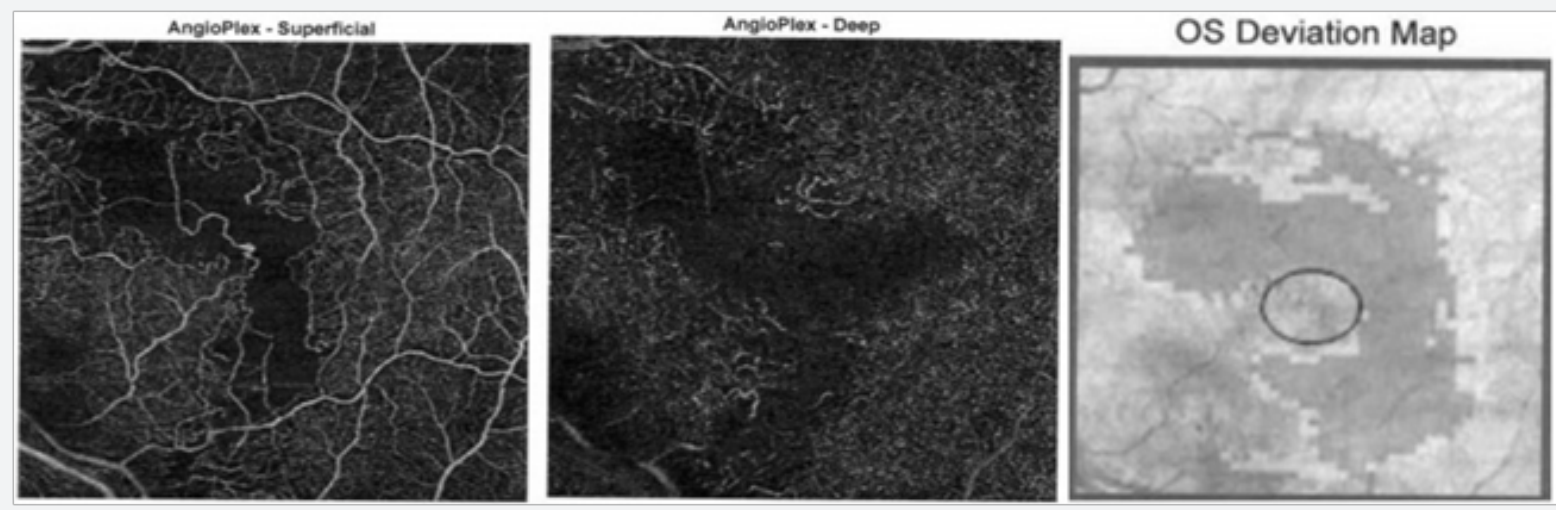

Figure 2: Example of decreased ganglion cell layer thickness in infero-temporal region not coincident to capillary non-perfusion areas detected in plexus.
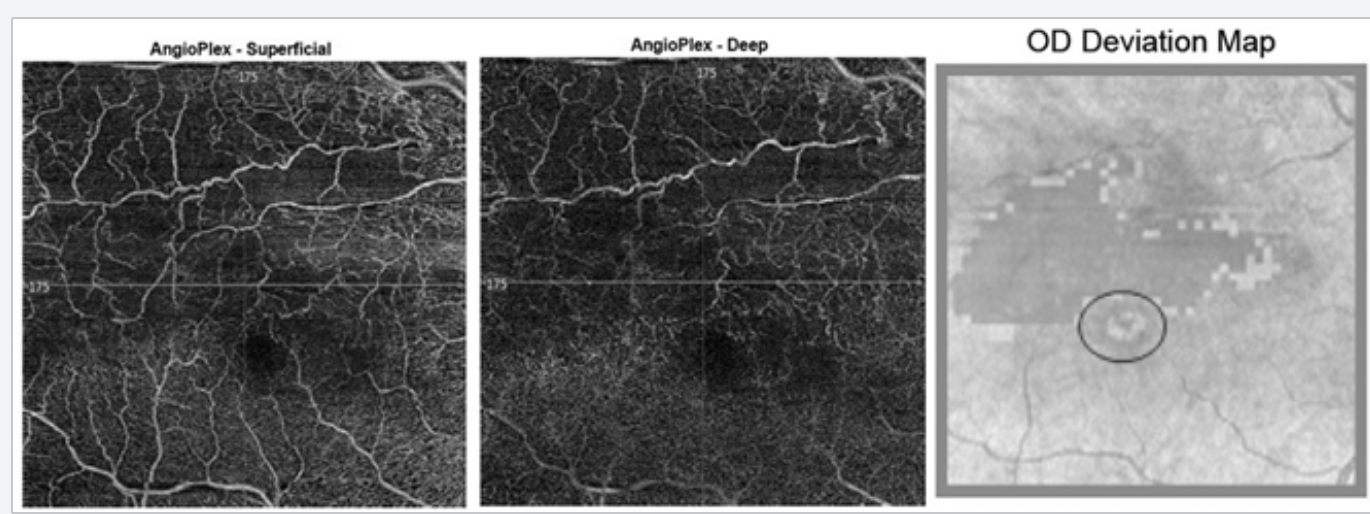

Figure 3: Example of capillary non-perfusion areas on plexus images that are not related with a reduction of the ganglion cell layer thickness.

\section{Discussion}

In BRVO eyes, the area of nonperfusion in deep capillary plexus tends to be larger than in superficial plexus. This is consistent with a recent publication where the authors concluded that nonperfusion grayish areas were more frequent in deep capillary plexus than in superficial capillary plexus $(\mathrm{p}<0.001)$. Bonnin et al. [5] highly suggested in their work that deep capillary vortexes are aligned along the course of the macular venules and drain into the superficial venules [6]. In RVO, the intravascular pressure increases in major veins, promoting a higher elevation in hydrostatic pressure in deep capillary, resulting in a perfusion decrease in the retinal tissues drained by the deep capillary plexus [7]. Moreover, the superficial capillary plexus is directly connected to the retinal arterioles, with a higher perfusion pressure and oxygen supply, and this may lead to a better preserved superficial capillary plexus than the deep capillary plexus in RVO [5], which is in keeping with our findings.

Our results also suggest that ischemic area, mainly of superficial plexus, seems to be related to a decreased thickness of inner retina, as it was correlated with the area of decreased RGC layer thickness. Our study is also in keeping with Lim HB et al. [8] who concluded that the thickness of macula, ganglion cellinner plexiform layer and retinal nerve fiber layer (RNFL) in the ischemic BRVO group was significantly reduced compared to the nonischemic BRVO group, especially in the RNFL [8].

Other areas of decreased RGC layer thickness, not related to ischemia, were detected suggesting that other pathophysiological mechanisms may be involved in the atrophy process (Figure 2). The coexistence of risk factors, like aging, diabetes, 
arteriosclerosis and macular edema may influence this findings $[1,9]$. On the other hand, ischemia can occur in the absence of retinal atrophy (Figure 3). Diffusion from adjacent vessels and the integrity of surrounding vasculature may play an important role. In addition, the detection of capillary non-perfusion areas on OCT-A could be also due to a very slow blood flow in these areas, below the threshold, giving a false negative result [10].

To the best of our knowledge, this is the first publication that correlates ischemic areas and reduced RGC layer thickness using OCT-A, providing new insights into the involvement of capillary plexus in inner retina atrophy.

Limitations of our study include the small number of cases, derived from the exclusion of many other patients based on the presence of some degree of fluid. Moreover, manual delineation of the areas provides some subjectivity to the analysis, although all delineations were approved by two retinal specialists.

\section{Conclusion}

This study suggests that ischemia may cause the decrease of RGC layer thickness, although other pathophysiological mechanisms may be involved. Larger sample size and prospective studies are needed to further support our results.

\section{Conflicts of Interest}

There are no conflicts of interest to report.

\section{References}

1. Ehlers J, Fekrat S (2011) Retinal Vein Occlusion: Beyond the Acute Event. Surv Ophthalmol 56(4): 281-299.

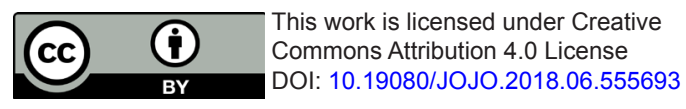

2. Spaide R, Klancnik J, Cooney M (2015) Retinal Vascular Layers Imaged by Fluorescein Angiography and Optical Coherence Tomography Angiography. JAMA Ophthalmol 133(1): 45-50.

3. Savastano M, Lumbroso B, Rispoli M (2015) In Vivo Characterization Of Retinal Vascularization Morphology Using Optical Coherence Tomography Angiography. Retina 35(11): 2196-2203.

4. Rispoli M, Savastano M, Lumbroso B (2015) Capillary Network Anomalies In Branch Retinal Vein Occlusion On Optical Coherence Tomography Angiography. Retina 35(11): 2332-2338.

5. Coscas F, Glacet-Bernard A, Miere A,Caillaux V, Uzzan J, et al. (2016) Optical Coherence Tomography Angiography in Retinal Vein Occlusion: Evaluation of Superficial and Deep Capillary Plexa. Am J Ophthalmol 161: $160-171$

6. Bonnin S, Mané V, Couturier A, Julien M, Paques M, et al. (2015) New insight into the macular deep vascular plexus imaged by Optical Coherence Tomography Angiography. Retina 35(11): 2347-2352.

7. Martinet V, Guigui B, Glacet-Bernard A, Zourdani A, Coscas G, et al (2012) Macular edema in retinal vein occlusion: correlation study between optical coherence tomography, fluorescein angiography and visual acuity. Int Ophthalmol 32(4): 369-377.

8. Lim HB, Kim MS, Jo YJ, Kim JY (2015) Prediction of Retinal Ischemia in Branch Retinal Vein Occlusion: Spectral-Domain Optical Coherence Tomography Study. Invest Ophthalmol Vis Sci 56(11): 6622-6629.

9. Rogers S, McIntosh R, Lim L, Mitchell P, Cheung N, et al. (2010) Natural History of Branch Retinal Vein Occlusion: An Evidence-Based Systematic Review. Ophthalmology 117(6): 1094-1101.

10. Tokayer J, Jia Y, Dhalla A-H, Huang D (2013) Blood flow velocity quantification using split spectrum amplitude-decorrelation angiography with optical coherence tomography. Biomed Opt Express 4(10): 1909-1924.

\begin{tabular}{|l|}
\hline \multicolumn{1}{|c|}{ Your next submission with Juniper Publishers } \\
will reach you the below assets \\
- Quality Editorial service \\
- Swift Peer Review \\
- Reprints availability \\
- E-prints Service \\
- Manuscript Podcast for convenient understanding \\
- Global attainment for your research \\
- Manuscript accessibility in different formats \\
( Pdf, E-pub, Full Text, Audio) \\
- Unceasing customer service \\
Track the below URL for one-step submission \\
https://juniperpublishers.com/online-submission.php \\
\hline
\end{tabular}

